\title{
Entre fe y saber: Habermas y el problema de la religión en una época postsecular
}

\author{
Between Faith and Knowledge: Habermas and The Problem of Religion in a \\ Post-Secular Age
}

\section{Franco Castorina}

Franco Castorina es becario doctoral del Consejo Nacional de Investigaciones Científicas y Técnicas, Argentina.

E-mail: fpcastorina@hotmail.com

\section{resumen}

El objetivo de este artículo es iluminar la relación particular que guardan religión y política en la época actual, a partir de la restitución de los aportes que Habermas ofrece al respecto. Para ello, en primer lugar, revisaremos la noción de "lingüistización de lo sagrado", con la cual el filósofo alemán pondera el lugar que la religión ocupa dentro del sistema de su Teoría de la acción comunicativa. En segundo lugar, examinaremos qué función ocupa la religión para Habermas, en el contexto de una era postmetafísica signada por la caducidad de todo discurso sostenido sobre la base de dogmas y verdades absolutas. En el tercer apartado, reconstruiremos el modo en que Habermas habilita la introducción de la religión al interior del espacio público, fundamentalmente en el marco de las democracias norteamericanas. Por último, inscribiremos los argumentos de Habermas sobre la relación entre religión y política en el contexto más amplio del debate sobre lo postsecular. En la conclusión, se recapitularán los argumentos presentados.

\section{palabras clave}

Habermas / religión / filosofía / postsecularismo / política

\section{summary}

The aim of the article is to shed light on the particular relationship between religion and politics in the present day, based on the restitution of Habermas's contributions in this regard. To this end, we will first review the notion of 'linguistization of the sacred', with which the German philosopher ponders the place that religion occupies within the system of his Theory of Communicative Action. Secondly, we examine what function religion occupies for Habermas, in the context of a post-metaphysical era marked by the expiry of any discourse sustained on the basis of dogmas and absolute truths. In the third section, we reconstruct the way in which Habermas enables the introduction of religion into the public space, fundamentally within the framework of North American democracies. Finally, we place Habermas's arguments about the relationship between religion and politics in the broader context of the post-secondary debate. We conclude by recapitulating the arguments presented.

\section{keywords}

Habermas / religion / philosophy / postsecularism / politics 


\section{Introducción: la caída de los absolutos y la crisis de la modernidad}

La frase de Nietzsche "Dios ha muerto" ha marcado el pulso de las reflexiones en torno al problema de la religión y de la legitimidad del orden político y social a lo largo del siglo XX. Autores de la talla de Carl Schmitt, Leo Strauss, Claude Lefort o Max Weber han contribuido al tratamiento de estos problemas, sea a través de la teología política (Schmitt, 2009), sea en virtud de la intrincada relación entre filosofía y fe (Strauss, 2008), sea por medio de una pregunta por la permanencia de lo teológico político (Lefort, 1988), o sea mediante un estudio sociológico de las religiones y de su impacto en las formas de vida sociales e individuales (Weber, 1998). En este sentido, la caída de todos los absolutos advertida por Hannah Arendt (1995) es una forma alternativa de nombrar el proceso de secularización en el cual estos autores inscriben la modernidad. De hecho, la atención brindada por buena parte de estos autores al régimen democrático no es para nada elocuente: en una era de relativismo axiológico, de pluralidad de valores y formas de vida, de ausencia de fundamentos últimos que den sentido a la totalidad social, la democracia aparece como la forma política más apta para canalizar esa pluralidad de convicciones personales.

No obstante, estas reflexiones han sido también motivadas por el fatal espejo de la democracia, pues los aciagos episodios totalitarios permanecen hoy en día en el horizonte del pensamiento europeo. Los fenómenos totalitarios han socavado de modo tan violento las bases de la civilización occidental que han planteado la necesidad de una revisión de conceptos metafísicos fundamentales como los de ser, historia, razón, o dios, por mencionar solo algunos. Pero, al mismo tiempo, estos fenómenos han supuesto la urgencia de no renunciar a principios universales capaces de dar respuesta al problema del relativismo de los valores y su nihilismo inherente. De estos problemas, motivados, por un lado, por la democracia y, por otro lado, por Auschwitz, ha formado parte Jürgen Habermas. Sus enormes esfuerzos por superar las amenazas de una época postmetafísica lo han conducido a su teoría de la acción comunicativa, asentada sobre una razón comunicativa que atiende a los procesos de justificación argumentativa y al ideal de comunicación. Sin intención de desarrollar esa propuesta, nuestro trabajo se propone reconstruir las reflexiones de Jürgen Habermas en torno a la religión. Si bien este tema no es central en la bibliografía habermasiana, sino más bien episódico, ha sido fruto de recurrentes tratamientos fundamentalmente en estos últimos años (Habermas, 2006, 2015). Este recorrido supone movilizar una serie de conceptos a partir de un doble movimiento: por una parte, mediante una restitución de la categoría de "lingüistización de lo sagrado", presente en su Teoría de la acción comunicativa; por otro lado, a través de la exposición de la función de la religión en una época postmetafísica. En este punto, seguimos a Juan Antonio Estrada, para quien el centro de la propuesta de Habermas radica en "una ética falibilista y procedimental, autónoma y formal, universalista y con potencial de aplicación a la variedad de culturas y contextos" (Estrada, 2004: 24). De allí que, para nosotros, el examen habermasiano en torno a la función de los discursos religiosos sea asumido desde una teoría de la comunicación de la cual se desprende una ética sin teología, falible y justificada argumentativamente. 
En suma, el objetivo del trabajo es iluminar la relación particular que guardan religión y política en la época actual, a partir de la restitución de los aportes que Habermas ofrece al respecto. Para ello, en primer lugar, revisaremos la noción de "lingüistización de lo sagrado", con la cual el filósofo alemán pondera el lugar que la religión ocupa dentro del sistema de su Teoría de la acción comunicativa. En segundo lugar, examinaremos qué función ocupa la religión para Habermas, en el contexto de una era postmetafísica signada por la caducidad de todo discurso sostenido sobre la base de dogmas y verdades absolutas. En el tercer apartado, reconstruiremos el modo en que Habermas habilita la introducción de la religión hacia el interior del espacio público, fundamentalmente en el marco de las democracias norteamericanas. Por último, inscribiremos los argumentos de Habermas sobre la relación entre religión y política en el contexto más amplio del debate sobre lo postsecular. En este marco, nos permitimos discutir con aquellos intérpretes que observan un "giro postsecular" en la obra de Habermas, caracterizado por el pasaje de un rechazo total de la religión hacia un diálogo entre filosofía y religión, a partir de la traducción del discurso religioso en los términos del lenguaje filosófico. La hipótesis que subtiende a nuestra interpretación, por el contrario, sostiene que existe una marcada continuidad entre los análisis que Habermas ofrece sobre la función de la religión en Teoría de la acción comunicativa y aquellos otros que realiza en sus textos más tardíos.

\section{La lingüistización de lo sagrado como racionalización comunicativa de la religión}

Si bien dejamos señalado el carácter episódico del tratamiento habermasiano de la religión, dicho tratamiento se inaugura a principios de los años sesenta, bajo la forma de artículos en los que Habermas se encuentra siempre atento a la relación de la religión y la teología con la filosofía, con el derecho y la moral; en suma, a su relación con el desarrollo y la evolución de la sociedad. En este sentido, sus reflexiones en torno a la religión iniciadas en la década del sesenta fueron el punto de partida para la formulación del concepto de lingüistización de lo sagrado en su obra fundamental, Teoría de la acción comunicativa.

El trasfondo sobre el cual se asienta el concepto de lingüistización de lo sagrado es una teoría de la racionalidad que Habermas reconoce en los aportes sociológicos de Max Weber. A partir de esta tipología de la racionalidad, Habermas ofrece un esquema de la sucesión de las diversas etapas en el desarrollo de las sociedades humanas sobre la base de su distinción analítica entre mundo de la vida y niveles de los sistemas. Por ello, Habermas procede a distinguir entre sociedades arcaicas o primitivas, tradicionales y modernas. Las diferencias en el desarrollo de las sociedades humanas están parcialmente motivadas por la brecha abierta entre la extensión y los niveles de perfeccionamiento en el subsistema de acción instrumental-intencional y la legitimación del poder. De hecho, el triunfo de las modernas sociedades capitalistas está vinculado con su éxito relativo en la armonización de las discordantes tendencias de la expansión de los subsistemas de acción instrumental y la legitimación de la coerción, aquello que Weber denominó racio- 
nalización de las formas de interacción. En cualquier caso, lo que debe destacarse es que la racionalización se ejecuta por una doble vía: 1) como expansión vertical de los subsistemas de acción instrumental que, en cada logro, va asumiendo cada vez más subsistemas de acción intencional. En esta línea, la lógica de la racionalidad estratégica-instrumental va ocupando cada vez más espacios, desterrando cualquier vestigio de la sociedad tradicional; 2) como pérdida de fuerza de las cosmovisiones, sean de raíz mitológica o religiosa.

Esto último es lo que, en la introducción, pudimos identificar, en línea con Weber, como secularización. Este término supone que las cosmovisiones tradicionales, como hemos dicho, pierden su poder y su estatus en tanto metafísicas o absolutos que dan sentido a la identidad individual y colectiva. En última instancia, el proceso de racionalización creciente conduce a que, como señala Eduardo Mendieta, en su introducción a Israel o Atenas. Ensayos sobre religión, teología y racionalidad, "no hay ya cosmovisiones 'tradicionales' que, rezagadas, como contracorriente arcaica, no estén ya sometidas al tribunal de la autojustificación racional. La tradición, sea religiosa o metafísica, debe ser justificada racionalmente" (Mendieta, 2011: 37). Ahora bien, ¿qué implica la racionalización de las cosmovisiones, o dicho en términos individuales, la racionalización de nuestras creencias? Como acertadamente advirtió Weber, parece ser que la racionalización de las cosmovisiones tradicionales nos ha abierto al ineluctable politeísmo de los valores. Al parecer, hemos de asumir nuestras existencias individuales en el mundo como algo absolutamente contingente, sin garantías, sin justificaciones, sin consuelos. Sin embargo, Habermas no cree que por esta razón la humanidad se encuentre entregada a la vacía autocomprensión cientificista y objetivante. A la pérdida de toda trascendencia portadora de unidad y sentido, Habermas localiza, en 1975, en un texto publicado en inglés llamado Legitimation Crisis, la clave para pensar una instancia que trasciende a los individuos dentro del mundo, es decir, alojada no en el cielo, sino en la tierra. En el decir de Jürgen Habermas:

La idea de Dios es transformada en el concepto de un Logos que determina la comunidad de creyentes y el contexto de vida real de una sociedad que se autoemancipa. "Dios" se convierte en un nombre para una estructura comunicativa que fuerza a los hombres, so pena de pérdida de su humanidad, a ir más allá de su naturaleza accidental, empírica, para encontrarse unos a otros, indirectamente, es decir, a través de algo objetivo que ellos mismos no son (citado en Habermas, 2011: 40). ${ }^{1}$

En esta modulación moderna del concepto de Dios, Habermas encuentra en el Logos, en el lenguaje y su función comunicativa, ese elemento que atribuye coherencia, unidad y consistencia a la trama del mundo de la vida. Dios es el nombre teológico de esa instancia lingüística que provee a los seres humanos la capacidad de reconocerse unos a otros como dadores de sentido. Dicho esto, habría que entender la teoría de la racionalización habermasiana como una reformulación de la teoría weberiana de la racionalidad. Esta reformulación se vincula a una teoría de la adquisición de competencias comunicativas, encaminada a "reconstruir la 
lógica del desarrollo de aquellos procesos de racionalización que han dirigido la diferenciación interna de los procesos de constitución de identidad, diferenciación social y legitimación política" (Mendieta, 2011: 42).

Sobre este trasfondo introducirá Habermas su concepto de lingüistización de lo sagrado. Para ello, se apoyará en los aportes de Mead y de Durkheim, ambos sobre la base de la pregunta por el desarrollo de estructuras universales y normativas como un desarrollo propio de las competencias lingüísticas y comunicativas. En este sentido, el enfoque de Mead autoriza a Habermas a reconstruir su teoría de la individuación como una teoría de la adquisición del lenguaje, de manera tal que la subjetividad aparezca como una instancia posterior a la intersubjetividad entendida como coetánea a la adquisición del lenguaje. De modo que la subjetividad es un atributo del individuo posterior a su carácter social o intersubjetivo, ya que antes de reconocerse y ser reconocido como sujeto, participa del lenguaje-de ese Logos que mencionamos unas líneas más arriba- como instancia intersubjetiva. Por otra parte, el examen que Durkheim dedica a las formas religiosas habilita a Habermas a reconstruir el desarrollo del orden social normativo como un proceso de integración simbólica en cuyo seno la solidaridad social cumple un rol preponderante. En línea con el tratamiento que Durkheim ofrece de la religión, Habermas subraya la raíz mítico-religiosa de las normas morales y sociales. Las creencias y rituales reconducen a un origen comunicativo de la religión tanto como a una identidad colectiva que se expresa y actualiza en rituales y cosmovisiones. Asimismo, los objetos sagrados poseen un estatuto simbólico en la medida en que "son lo que significan", es decir, en tanto "figuran como signos con un significado convencional, y tienen todos el mismo núcleo semántico; representan el poder de lo santo" (Habermas, 1992: 77).

En función de estos aportes teóricos, Habermas perseguirá la forma en la que las cosmovisiones metafísicas y religiosas son lingüistificadas, esto es, accesibles para agentes constituidos simbólicamente en virtud de su apertura al medio discursivo o lingüístico, motivado por la idea de que solo a través de la acción comunicativa pueden ramificarse las energías de solidaridad social ligadas al simbolismo religioso y comunicarse como autoridad moral, lo mismo a las instituciones que a las personas. Solo mediante el desencantamiento y la pérdida de poder del dominio sagrado, vía su lingüistización, se acomete la liberación del poder vinculante y normativo, alojado en aquellos acuerdos normativos realizados bajo la forma ritual. En palabras de Habermas:

El desencantamiento y depotenciación del ámbito de lo sagrado se efectúa por vía de una lingüistización del consenso normativo básico asegurado por el rito; y con ello queda a la vez desatado el potencial de racionalidad contenido en la acción comunicativa. El aura de encandilamiento y espanto que lo sacro irradia, la fuerza fascinante de lo santo se sublima al tiempo que se cotidianiza, al trocarse en la fuerza vinculante de pretensiones de validez susceptibles de crítica (Habermas, 1992: 112). 
Es la ritualización de la religión, transformada, por este hecho, en tradición, la que otorga la posibilidad de apropiarla reflexivamente y abrirla a la crítica. El poder aterrador de lo divino queda sublimado bajo la forma de normas sociales vinculantes en virtud de su lingüistización. Sucede que, si a través de un símbolo religioso, una comunidad de creyentes se constituye como grupo, la propia práctica lo desacraliza, de modo tal que el poder que el mito proyecta sobre los humanos es convertido en la coacción no coercitiva de las normas sociales. De esta manera, como señala Mendieta "la separación entre lo profano y lo sagrado corresponde a una grieta en el medio de comunicación, a saber, la escisión que tiene lugar entre los usos proposicionales, expresivos y normativos del lenguaje" (Mendieta, 2011: 46). En este sentido, lo religioso no queda atrás, sino que se interioriza en la sociedad, pues, como dejamos asentado, el poder normativo alojado en los contextos rituales religiosos queda liberado por la acción comunicativa. En última instancia, la lingüistización de lo sagrado remite a una cotidianización de lo santo, en donde "la coacción ejercida por lo 'totalmente Otro' se transforma en acontecimiento cotidiano que debemos vivir en términos de respeto por la fuerza vinculante de normas de acción y máximas morales" (Mendieta, 2011: 48).

Este es el esquema que domina el tratamiento habermasiano de la religión, al menos hasta Teoría de la acción comunicativa. La lingüistización de lo sagrado, como ha quedado expuesto, alude a una suerte de racionalización -en términos de racionalidad comunicativa- de los contenidos normativos de la religión, con vistas a asegurar normas sociales no coactivas. Por ello, tiene razón Habermas cuando escribe:

No son ni la ciencia ni el arte los que recogen la herencia de la religión; sólo la moral convertida en "ética del discurso", fluidificada comunicativamente, puede en este aspecto sustituir a la autoridad de lo santo. En ella queda disuelto el núcleo arcaico de lo normativo, con ella se despliega el sentido racional de la validez normativa (Habermas, 1992: 132).

Como hemos mencionado, estamos en presencia de una racionalización de contenidos normativos sagrados, una racionalización que consiste en el paso de la interacción simbólica a la interacción verbal; del consenso consuetudinario de lo sagrado, a la fundamentación racional de principios universales comunicativamente mediados; por último, asistimos a un pasaje de los esquemas míticos, metafísicos y religiosos a otros asentados sobre la crítica reflexiva y la racionalidad ética. Concluiremos este apartado oyendo nuevamente los ecos de Habermas:

A medida que el lenguaje se impone como principio de socialización, las condiciones de sociabilidad convergen con las de la intersubjetividad creada comunicativamente. Simultáneamente la autoridad de lo santo queda trasvasada a la fuerza vinculante de que están dotadas unas pretensiones de validez normativas, que sólo pueden desempeñarse de forma discursiva (Habermas, 1992: 134). 


\section{La religión en el pensamiento postmetafísico}

En los últimos años, la cuestión de la religión ha sido un tema más frecuente y elaborado en los trabajos de Jürgen Habermas. La atención brindada a la religión durante este último período tiene como horizonte la comunidad de creyentes del Estado secular norteamericano y de sus sociedades liberales presuntamente tolerantes. Asimismo, esa reflexión no deja de estar motivada, aunque en menor medida, por el problema de los fundamentalismos religiosos que, en cierto modo, reactualizan un sustancialismo que Habermas pretende dejar atrás. En vista de estos problemas, el presente apartado propone reponer algunos problemas planteados en sus libros Pensamiento postmetafisico, Entre naturalismo y religión y Mundo de la vida, política y religión [Nachmetaphysisches Denken II] en lo atinente al estatuto de la religión dentro de un pensamiento postmetafísico.

El primer problema que debe enfrentar Habermas se sitúa en la discusión en torno a la tesis de la secularización. En este punto, se ha creído ver en la lingüistización de lo sagrado una conceptualización de la secularización en términos de superación total de la religión. Sin embargo, Habermas no entiende que haya habido una superación de los contenidos semánticos de la religión que atentan contra la supervivencia de las comunidades religiosas en una sociedad postsecular. Al contrario, como deja señalado:

Utilizo la expresión "postsecular" para la descripción sociológica de un giro tendencial de la conciencia en las sociedades ampliamente secularizadas o "desclericalizadas", que, entretanto, se han orientado a la perduración de las comunidades religiosas y que cuentan con el influjo de las voces religiosas tanto en la esfera pública nacional como en el escenario de la política internacional (Habermas, 2015: 109).

En efecto, la hipótesis dominante durante largo tiempo en las disciplinas de la filosofía y, fundamentalmente, de la sociología, de que entre la modernización progresiva de la sociedad y la supervivencia de las comunidades religiosas existe un juego de suma cero ha sido puesta en tela de juicio. En este sentido, si bien Habermas reconoce que las tradiciones religiosas se distinguen de modo cabal respecto de la filosofía - pues posee una base de justificación de sus "verdades" muy diferente y, además, porque se apoya en la estabilidad de la fe reproducida mediante prácticas de culto de una comunidad de creyentes-, considera a la religión como un discurso legítimo de la modernidad, cuyas interpretaciones acerca del yo y del mundo pertenecen a esa variedad de perspectivas propias del pensamiento postmetafísico que conviven en la actualidad. De allí que los discursos religiosos pervivan y convivan al lado de otros discursos seculares como los de la filosofía, la sociología o las ciencias naturales en el marco del pensamiento postmetafísico. En efecto, Habermas corrobora esta idea cuando afirma in extenso que:

La religión, que en gran parte ha quedado privada de sus funciones de imagen del mundo, sigue siendo insustituible, cuando se la mira desde fuera, para el trato normalizador con lo extracotidiano de lo cotidiano. De ahí también que el pensamiento postmetafísico coexista aún con 
una praxis religiosa. Y ello no en el sentido de la simultaneidad de lo asimultáneo. La continuidad de esta coexistencia ilumina incluso una curiosa dependencia de una filosofía que ha perdido su contacto con lo extracotidiano. Mientras el lenguaje religioso siga llevando consigo contenidos semánticos inspiradores, contenidos semánticos que resultan irrenunciables, pero que se sustraen (¿por el momento?) a la capacidad de expresión del lenguaje filosófico y que aguardan aún quedar traducidos al medio de la argumentación racional, la filosofía, incluso en su forma postmetafísica, no podrá ni sustituir, ni eliminar a la religión (Habermas, 1990: 62-63, cursivas nuestras).

Esta última cita cierra afirmativamente la pregunta por la pervivencia de la religión en el esquema del pensamiento postmetafísico, pero, asimismo, abre a la pregunta por esos contenidos semánticos irrenunciables que la filosofía intenta traducir a la argumentación racional. Es que la permanencia de la religión en una sociedad postsecular no puede ser tomada como un simple dato sociológico, sino que debe atendérselo como un desafío cognitivo para la filosofía. Por ello, la filosofía, por un lado, consciente de su carácter falible y de su frágil posición hacia el interior de la compleja sociedad moderna, "insiste en la diferenciación genérica, pero de ningún modo peyorativa, entre el discurso secular que aspira a ser accesible a todo el mundo y el discurso religioso dependiente de las verdades reveladas" (Habermas, 2006: 115). Sin embargo, por otro lado, la filosofía no emite juicios respecto de la veracidad de los contenidos de las tradiciones religiosas, pues respeta las formas de vida de las personas que abrevan en convicciones de orden religioso. En efecto, para Habermas la filosofía "tiene razones para mantenerse dispuesta al aprendizaje ante las tradiciones religiosas" (2006: 115), pero, del mismo modo, la religión se halla abierta, también, a un aprendizaje de las mentalidades mundanas. ${ }^{2}$ Tal es así que "ambas partes, si conciben la secularización de la sociedad como un proceso de aprendizaje complementario, pueden realizar sus contribuciones a los temas controvertidos en la esfera pública y tomarse en serio recíprocamente también por motivos cognitivos" (Habermas, 2006: 117). En este sentido, el pensamiento postmetafísico no tiene motivos para excluir la posibilidad de una siempre continua emigración de contenidos teológicos al ámbito secular. Sin embargo, “desde la visión postmetafísica una 'traducción' no debe pagarse al precio de un regreso a la unidad de una razón sustancial que obra con energía a través de la historia o que se encarna en el cosmos" (Habermas, 2015: 119). La validez de los contenidos teológicos requiere, para Habermas, una emigración a lo secular, entendida en términos de distinción de fronteras discursivas entre "los discursos de la fe y los discursos de la ciencia" (Habermas, 2015: 119). Pero, entonces, ¿cuál es la especificidad del discurso religioso que lo hace particularmente valioso para un aprendizaje filosófico? Habermas responde:

Por eso en la vida de las comunidades religiosas, en la medida en que logren evitar el dogmatismo y la coerción sobre las conciencias, permanece intacto algo que en otros lugares se ha perdido y que 
tampoco puede ser reproducido con el solo saber profesional de los expertos: me refiero aquí a las posibilidades de expresión y a sensibilidades suficientemente diferenciadas para hablar de la vida malograda, de las patologías sociales, de los fracasos de proyectos vitales individuales y de la deformación de los contextos de vida desfigurados (Habermas, 2006: 116).

La filosofía debe estar atenta al diálogo con la religión, pues cabe fundamentar esta disposición al aprendizaje en términos de contenido. En ese momento salvador del que abreva toda religión monoteísta, es señalado un destino colectivo que va más allá de cualquier felicidad personal, pues hace al trasfondo de una conciencia de crisis que conmueve a la humanidad toda. De allí que la filosofía encuentra en la religión aprendizajes de índole tanto ético como cognitivo bajo la forma de la solidaridad social. La moral racional realiza una apropiación filosófica de contenidos religiosos no amortizados en vistas de su carácter universal. Esto, a su vez, implica que la filosofía incorpora contenidos semánticos no amortizados de la religión, en virtud de su pretensión de universalidad, es decir, sin incorporar ningún concepto vinculante de vida buena, pues al pensamiento ético postmetafísico esos conceptos le son totalmente ajenos. En este sentido, la estrategia de Habermas en su análisis de la religión se lleva a cabo a partir de un doble movimiento vinculado a un ateísmo metodológico y al agnosticismo.

El ateísmo metodológico supone la imposibilidad de renunciar a la autoridad de la razón secular en términos de su valor cognitivo, aunque esta misma razón encuentre en su camino un núcleo completamente racional e inmanente de convicciones religiosas. Sin embargo, ante los contenidos semánticos de la religión, la filosofía se declara agnóstica, incompetente para determinar el estatuto de su pretensión de verdad. En el decir de Habermas,

cuando el agnóstico se abstiene de decidir sobre una pretensión de validez, está expresando su incomprensión frente a un género discursivo; pues, desde su punto de vista, las 'verdades' religiosas son formuladas en una trama de conceptos que precede a la diferenciación habitual en enunciados descriptivos, evaluativos y normativos (2015: 130).

En vistas de este doble movimiento, queda aún más fundamentada la distinción entre registros discursivos que previamente señalamos. Por ello, si bien la filosofía se encuentra abierta al aprendizaje de una tradición religiosa que une

la dimensión cognitiva de la autocomprensión y de la comprensión del mundo con la dimensión social de la pertenencia a una asociación universal, que (desde el punto de vista secular) sostiene una vinculación con las fuentes arcaicas de la solidaridad (que para la parte secular están cegadas) (Habermas, 2015: 131)

El reconocimiento de ese impulso cognitivo y la probable continuación de un proceso de traducción de contenidos religiosos a un lenguaje secular no debe per- 
suadir a la filosofía hacia la "imitación mistificadora de actitudes religiosas. El ateísmo metódico obliga a un discurso fundamentado, en general discursivo, que opone resistencia a la furtiva introducción retórica de teologúmenos" (2015: 134). Todo el tratamiento de la religión conducido hasta aquí nos advierte de la relevancia de la dimensión religiosa en las sociedades postseculares. Por ello, el próximo apartado esbozará las líneas fundamentales a partir de las cuales Habermas elabora el rol de la religión en el espacio público político, esto es, se ocupa de la relación que existe entre la religión y la política.

\section{El rol de la religión en el espacio público}

La pregunta por el rol de la religión en el ámbito público de la política se inaugura desde un punto de partida que es preciso señalar, a saber, "que los ciudadanos democráticos se deben recíprocamente los argumentos para sus posicionamientos políticos" (Habermas, 2015: 135). Ahora bien, esta idea preliminar se ve en dificultades ante ciertas constituciones liberales que, aunque apuntan hacia el aseguramiento de la libertad de movimiento y de la igualdad de derechos para todos sus ciudadanos, "protegen al mismo tiempo a las corporaciones estatales que toman resoluciones colectivas vinculantes contra las influencias religiosas" (Habermas, 2015: 135).

El problema queda iluminado: una sociedad pluralista, asentada sobre el principio de la tolerancia, habilita expresamente a ciertos ciudadanos creyentes a practicar una religión y a llevar a cabo una vida piadosa y, sin embargo, al mismo tiempo, con el resultado del proceso democrático, les niega toda presencia religiosa. Esta respuesta al problema, eminentemente laica, que supone la expulsión de la religión del ámbito público, no da con la solución. En este sentido, "mientras las comunidades religiosas desempeñan un papel vital en la sociedad civil, no se ajusta al sentido de las constituciones liberales censurar las voces de los ciudadanos religiosos ya en la fuente misma de la formación de la voluntad democrática" (Habermas, 2015: 136). La exclusión de las voces de los ciudadanos religiosos no es plausible para Habermas, pues él parte de la exigencia normativa de un reconocimiento mutuo de ciudadanos con iguales derechos que poseen el estatuto de colegisladores.

La respuesta habermasiana al problema de las comunidades religiosas en el ámbito público se vincula a cuestiones ya tratadas en el apartado anterior, pero que bien vale reforzar. De acuerdo con Habermas, "las contribuciones religiosas tienen que ser traducidas a un lenguaje de acceso universal, antes de que su contenido pueda encontrar entrada en las deliberaciones de aquellas instituciones políticas que toman decisiones jurídicamente vinculantes" (2015: 136, cursivas nuestras). Esto supone la aceptación del valor de los enunciados públicos de orden religioso, en la convicción de que, aunque formulados en un lenguaje religioso, poseen un posible contenido cognitivo accesible de traducción. Por ello, una sociedad pluralista constituida en términos liberales se funda en el principio de la tolerancia que exige no sólo a los creyentes que adopten en el trato con los no creyentes y heterodoxos la actitud de tener que contar razonablemente con 
la persistencia de un disenso. Por el otro lado en el marco de una cultura política liberal se exige la misma actitud a los no creyentes en el trato con los creyentes (Habermas, 2006: 118).

Los términos de la reflexión de Habermas se mueven siempre en los límites de la frontera trazada entre saber y fe, desde la perspectiva de un saber mundano, es decir, en línea con un ateísmo metodológico que no denuncia la falsedad de los contenidos religiosos, pues se declara agnóstico. En este sentido, hay que insistir en el estatus epistémico de las convicciones religiosas que obliga a las sociedades pluralistas a atenderlas en el marco de un espacio público político. Las imágenes del mundo naturalistas, esto es, elaboradas en virtud de parámetros científicos que son relevantes para la autocomprensión ética de los ciudadanos, no gozan de ninguna manera de una prioridad ante las cosmovisiones religiosas. Ambas son igualmente plausibles en el interior del ámbito público político. Tal es así que:

La neutralidad del poder estatal en lo que respecta a las cosmovisiones, neutralidad que garantiza iguales libertades éticas a todos los ciudadanos, no es compatible con la generalización política de una visión del mundo secularista. En principio, los ciudadanos secularizados, en la medida en que actúen en su papel de ciudadanos de un Estado, no deben negarles a las imágenes del mundo religiosas un potencial de verdad, ni deben cuestionarles a los conciudadanos creyentes el derecho a hacer aportaciones en el lenguaje religioso a las discusiones públicas. Una cultura política liberal incluso puede esperar de los ciudadanos secularizados que participen en los esfuerzos de traducir las contribuciones relevantes desde un lenguaje religioso a un lenguaje públicamente accesible (Habermas, 2006: 119).

El rol de la religión en el ámbito público político supone su participación activa en la consecución de normas jurídicamente vinculantes llevadas a cabo por las instancias estatales. Por ello, un secularismo público es insuficiente, en la medida en que no toma en serio a los ciudadanos creyentes, a raíz de su mentalidad religiosa. Una verdadera sociedad pluralista y multicultural ${ }^{3}$, atenta a la multiplicidad de formas de vida sociales, pone en práctica una traducción de aquellos contenidos religiosos cognitivamente pertinentes a los efectos de generar normas jurídicas vinculantes. Sin embargo, puede uno formularse la pregunta acerca de la accesibilidad universal de ese lenguaje al que hace mención Habermas, un lenguaje vinculado evidentemente a la razón comunicativa propia de las sociedades postseculares, así como al pensamiento postmetafísico. Esto nuevamente se asocia a la distinción entre fronteras discursivas religiosas y seculares, pero, asimismo, convoca la pregunta por la accesibilidad universal de esos enunciados que traducen el lenguaje religioso.

"Solo bajo la premisa de la razón humana 'natural', común a todos, las partes beligerantes han conseguido adoptar en las confrontaciones políticas un punto de vista común más allá de las fronteras sociales de la propia comunidad de creyen- 
tes" (Habermas, 2015: 139). En la razón humana "natural" encontrará Habermas el punto de apoyo a partir del cual superar aquello que Weber diagnosticó como "la guerra a muerte entre dioses", entre valores. Recordemos que, desde un punto de vista histórico, fueron en parte las cruentas consecuencias de las confrontaciones entre poderes creyentes los que concitaron el proceso de secularización del poder del Estado. Hasta ese punto, esas partes no habían podido encontrar una solución dentro de la comunidad política. En este sentido,

sólo con la traducción del núcleo universalista de las propias convicciones religiosas fundamentales en los principios de los derechos humanos y de la democracia, fundamentados racional y jurídicamente, han encontrado un lenguaje común más allá de las diferencias de fe irreconciliables (Habermas, 2015: 139).

Por lo tanto, solo a partir de esa razón que provee de un lenguaje común las comunidades religiosas han logrado salir de sus pretensiones de validez particularistas empeñadas en ampliarse a escala mundial. En este punto, no asombra esta salida habermasiana, muy en línea con el concepto de lingüistización de lo sagrado: lo que acomuna a los seres humanos, a pesar de sus diferencias de fe, es esa modulación secularizada de Dios vinculada a un Logos, a una razón comunicativa que permite a los hombres trascender sus propias conciencias e individualidades y que evidencia el carácter co-constitutivo de la intersubjetividad. Solo que ahora se trata de una moral racional y de un derecho que proyectan un "nosotros" inclusivo, que obliga a todas las partes por igual a un aprendizaje común, a un reconocimiento recíproco de perspectivas, "en cuyo transcurso se funden, unos con otros, los puntos de vista particulares en un horizonte común ampliado (Gadamer)" (Habermas, 2015: 139-140).

De lo que se trata, en última instancia, es de distinguir correctamente entre concepciones de la "buena vida", esto es, de proyectos existenciales que encierran formas de vida y orientaciones axiológicas, de aquellos estándares universales de justicia.

De ahí que los ciudadanos religiosos estén ante la doble tarea de fundamentar, una vez más, desde el contexto de su fe, los principios constitucionales fundamentados secularmente además de -y esta es la mayor dificultad-reconocer la diferencia entre argumentos públicos falibles y verdades de fe infalibles (Habermas, 2015: 140).

Esto implica que para las verdades de los enunciados se exige una validez universal en un sentido diverso a aquellas de las certezas de la fe. Los enunciados presentan un sentido descentrante de universalidad, que supone que están abiertos siempre a una reactualización en su carácter de enunciados falibles. Las verdades de la fe, por su parte, no reconocen su falibilidad, pero deben reconocer, como ciudadanos activos de un Estado constituido democráticamente, la relevancia política de esta distinción entre ambos tipos de pretensiones de verdad. El reconocimiento de esta ambivalencia es la condición de posibilidad de una sociedad pluralista que tiene en cuenta a todos sus ciudadanos por igual. En este marco, la traducción 
supone "la necesidad de examinar, en los contextos de formación política de la voluntad de una sociedad pluralista, el contenido de verdad de los enunciados religiosos independientemente del contexto epistémico de origen" (Habermas, 2015: 140). Solo en la medida en que nos desprendamos de la pretensión de verdad infalible, propia de la fe, y abracemos un ámbito público político racionalmente fundamentado a partir de argumentos que asuman su carácter falible, estaremos en condiciones de afirmar la democracia y los derechos humanos.

Sin embargo, ante la diferenciación habermasiana entre cuestiones universalistas de justicia y cuestiones particularistas de bien, esto es, frente a la distinción entre lo justo y lo bueno, entre lo justo y los valores, nos preguntamos si en verdad, en el trasfondo de su teoría, Habermas no oculta una apuesta axiológica por el diálogo y por la racionalidad comunicativa bajo el principio aparentemente formal y universal de una ética discursiva. Es decir, reconocer que el diálogo entre el discurso religioso y el filosófico solo es posible bajo la forma de una traducción de contenidos religiosos al lenguaje secular equivale a sostener una noción de discurso que únicamente es tal en cuanto tiene por efecto la pluralidad. Esto, asimismo, implica la sumisión de todo discurso religioso a discurso filosófico -y no a cualquier noción de filosofía, sino a una noción liberal de filosofía-, en la medida en que la "accesibilidad" del discurso religioso solo es posible mediante su traducción al Logos, esto es, a través de su reducción a las reglas de la filosofía, lo cual equivale a afirmar valorativamente - pero no a demostrar argumentativamente- la superioridad de la filosofía liberal por sobre la religión (iy por sobre cualquier otra forma de filosofía!). Por esto, consideramos que en el fondo de esa convivencia entre discursos filosóficos y discursos religiosos se expresa una actitud valorativa que reduce todo discurso en clave moralizante. En tal caso, serían discursos solo aquellos que por principio alberguen la pluralidad. Una moralización de este tipo parece condenar todo discurso de índole no plural, identificando a sus portadores como enemigos de lo público, y desconociendo su estatuto de sujetos de discurso. Tal vez sea este peligro el que desconocen aquellos que identifican en Habermas un "giro postsecular" en su obra. ${ }^{4}$ Procuraremos concluir, entonces, reconstruyendo el debate en torno al postsecularismo, como marco a partir del cual podemos comprender el carácter moralizante que Habermas imprime a las relaciones existentes entre religión y política en sociedades postmetafísicas.

\section{El postsecularismo ${ }^{5}$ como pluralismo normativo y axiología pluralista}

En el debate contemporáneo, una serie de autores (Gamper, 2009; Ungureanu, 2013; Roldán Gómez, 2017) han identificado un "giro postsecular" en la obra de Jürgen Habermas. Si bien sus valoraciones con respecto a la noción de lo postsecular son disímiles, todos ellos concuerdan en que Habermas modifica su evaluación en torno al rol de la religión y a su influencia en la construcción democrática del espacio público. A un primer momento de su obra eminentemente secular, caracterizado por el rechazo del dogma religioso, le sucedería una reevaluación de la religión, que reconoce en ella aspectos positivos capaces de contribuir beneficiosamente en el debate público democrático. 
$\mathrm{Al}$ respecto, Ungureanu interpreta este secularismo inicial de Habermas en una clave metafísica. De acuerdo con su lectura, la clave hermenéutica para comprender este primer período de la obra de Habermas es la filosofía de la historia sobre la cual se sostiene (2013: 186). En línea con Kant, Habermas apoya su teoría de la razón comunicativa sobre la base de una filosofía de la historia, comprendida como un progreso lineal, en cuyo camino la religión ocupa un papel relevante, aunque secundario. No obstante, Ungureanu se cuida de inscribir a Habermas en la saga de las filosofías de la historia propias del idealismo alemán del siglo XIX: "Habermas rechaza la idea de necesidad histórica, pero sostiene que el desarrollo histórico muestra una lógica progresiva -la de la evolución gradual del potencial racional que se encuentra incorporado en cada acción comunicativa" (2013: 186). Dicha filosofía de la historia constituiría una versión más de la teoría de la secularización, en la cual las religiones universales -fundamentalmente el cristianismo- jugarían un papel importante en el proceso histórico de revelación progresiva de la razón.

Sin embargo, dicho potencial racional de las religiones universales quedaría limitado por la perpetuación de las desigualdades de clase que las propias religiones promueven. Según Ungureanu, es aquí donde se hace patente la deuda que Habermas tiene con Marx, en lo tocante a la comprensión de la religión como ideología. La religión, lejos de poner en entredicho las condiciones de clase que reproducen la injusticia y el sufrimiento, funge de ideología que camufla y legitima dichas condiciones. El contenido racional que exhiben las religiones universales se diluye ante la inmunidad que establecen contra toda objeción que pueda presentarse en la comunicación cotidiana, reproduciéndose a sí mismas de forma dogmática. El corolario es la construcción de la legitimidad democrática sobre la base de una ética discursiva, en cuyo seno la religión es excluida.

Años más tarde, específicamente en 1989, en el contexto de la caída del muro de Berlín, Habermas acusa un desplazamiento en la evaluación de la religión. La literatura especializada habla de esta reevaluación en términos de un "giro postsecular" en la obra de Habermas. Este giro obedece a la preocupación de Habermas por la falta de solidaridad entre los ciudadanos en sociedades secularizadas, sumado a la escasa motivación para participar de la esfera pública (Ungureanu, 2013: 187). Asimismo, luego de 1989, la tesis clásica de la secularización, es decir, la identificación de la modernización como una tendencia inevitable hacia la decadencia de la religión, pierde su fuerza. En reemplazo, ciertos sociólogos proponen sustituir la tesis de la secularización por la idea de la "desprivatización" (Casanova, 1994, 2000, 2008) y la "desecularización" (Berger, 1999) de la religión. Con esta nueva terminología, advierten la imposibilidad de postular una incompatibilidad entre modernidad y religión, al mismo tiempo que reconocen la necesidad de repensar el vínculo existente entre la religión y la esfera pública.

Gamper (2009) también reconoce esta variación que se produce en la contemporaneidad y a la que alude asimismo con el concepto de "desecularización", aunque su mirada es aún más sociológica que las mencionadas anteriormente. Si la desecularización nos informa de una desprivatización de la religión, de una creciente legitimación de la participación de los discursos religiosos en el debate público y, 
por tanto, en las decisiones institucionales del Estado, es precisamente porque la religión vuelve a proporcionar un marco de identidad al individuo. En el marco de la secularización, se admitía la posibilidad de que cada Estado permitiera a sus ciudadanos escoger libremente una confesión, sin interferir en esa creencia a la que cada uno quisiera vincularse (Gamper, 2009: 113-114). Con la desecularización, se radicaliza este movimiento, de manera tal que la elección individual de una confesión no solo debe ser respetada, sino que debe ser "oída" en la esfera pública. La religión renueva su función identitaria, en la medida en que es el producto del ejercicio de la libertad individual de los ciudadanos $y$, en tanto tal, debe ser atendida por el Estado.

Es este contexto académico de reflorecimiento de la reflexión sobre la religión el que refuerza la preocupación de Habermas por la relación entre religión y política y lo conduce a pensar la noción de postsecular o postsecularismo. Como ya hemos señalado, esta noción da cuenta de un cambio de tendencia inherente a las sociedades seculares de Europa y Estados Unidos, en virtud del cual la religión no solo persiste en el interior de Estados laicos, sino que sus discursos ganan consistencia y participación en el espacio público. En definitiva, como señala Roldán Gómez, "lo 'postsecular' pone en relación dos dinámicas en principio opuestas: por un lado, la secularización; por otro lado, las injerencias religiosas en la esfera pública que no se disuelven a pesar de esa secularización" (2017: 853). Ahora bien, es posible identificar una doble acepción en el término postsecularización. En primer lugar, lo postsecular asume una dimensión descriptiva, que refiere a la persistencia de la religión en sociedades y Estados eminentemente seculares, esto es, en ordenamientos jurídico-políticos que distinguen y separan jurídicamente las instituciones religiosas de las instituciones públicas. En este sentido, podemos hablar de Estados Unidos o de Alemania - por mencionar solo dos ejemplos- como sociedades seculares, en cuyo seno aún conviven ciudadanos ateos y ciudadanos creyentes. En segundo lugar, lo postsecular admite una dimensión normativa, en la medida en que la persistencia religiosa exige una reflexión acerca del lugar de la religión en la esfera pública (Roldán Gómez, 2017: 853-854).

Aquí interesa especialmente la dimensión normativa que adquiere el concepto de postsecularismo, es decir, la pregunta por la relevancia de la religión en el espacio público, y por el modo en que el discurso religioso puede participar en dicho espacio. En el cuarto apartado hemos abordado el análisis que Habermas dedica al rol de la religión en el espacio público. De dicho examen, Habermas desprende la necesidad de una traducción de los discursos religiosos al lenguaje secular de la filosofía y de las instituciones públicas del Estado. Este corolario amerita una serie de preguntas: ¿qué implica una traducción de los discursos religiosos al lenguaje secular? ¿No implica la traducción una pérdida de ese discurso religioso? ¿La traducción al lenguaje secular no vuelve superflua la noción misma de lo postsecular? ¿En qué medida se puede hablar de la inclusión del discurso religioso, si dicha inclusión se produce al precio de la supresión de su contenido específico? La respuesta de Habermas a la pregunta por cómo incluir a la religión en el espacio público no deja de ser una respuesta, por insatisfactoria que sea. Si la participación 
de los discursos religiosos enunciados por ciudadanos creyentes se realiza a través del tamiz de una traducción que suprime su contenido específico, ¿en qué medida podemos hablar de una persistencia del discurso religioso en la esfera pública?

Está claro que la preocupación "postsecular" de Habermas obedece a un ideal normativo que pretende, de alguna manera, reconciliar la religión con la política y la filosofía, el cielo y la tierra. El debate con Ratzinger es una clara muestra de ello (Habermas y Ratzinger, 2013). Sin embargo, la solución habermasiana de la traducción evidencia la imposibilidad de llevar a cabo ese ideal. Si el discurso religioso debe ser traducido a un lenguaje secular es porque, para Habermas, en el fondo de ambos lenguajes hay una desavenencia fundamental, que impide su convivencia. Lo postsecular se descubre como un pluralismo normativo, como una aspiración a la pluralidad, en cuyo seno el discurso religioso es imposible, porque aspira a lo absoluto y a lo universal y por ello acude a parámetros de justificación infalibles.

El "giro postsecular" al que hacen referencia ciertos autores es cierto solo si admitimos que se trata de un giro nominalista, es decir, solo si aceptamos que Habermas intercambia la noción de secularización por el término aparentemente más pluralista de postsecularización. Nuestra hipótesis es que Habermas sostiene la misma concepción de la religión que lo acompaña desde Teoría de la Acción Comunicativa. En este sentido, el concepto de lingüistización de lo sagrado apenas si difiere del de traducción. En el ínterin, lo que varía es una elaboración mucho más acabada de lo que es el espacio público, dentro del cual la relación entre lo religioso y lo político no se altera. En definitiva, detrás del concepto de lo postsecular se oculta una moralización de la palabra pública que impide la enunciación de todo discurso que no tenga por efecto la pluralidad y que conmina a estos últimos al ostracismo. Habermas encubre, tras el manto sagrado de una ética discursiva aparentemente formal y universal, una apuesta axiológica por el diálogo, en el que, no obstante, reinan determinadas reglas y criterios de justificación, y en el cual el discurso religioso no tiene lugar. En esto -creemos- reside el problema fundamental del postsecularismo fallido de Habermas, que señala, por lo demás, la dificultad que padece toda teoría filosófica para desprenderse de la pregunta por el contenido de lo Bueno.

\section{Consideraciones finales}

En este artículo hemos pretendido mostrar el papel de la religión en la obra de Jürgen Habermas. A lo largo de nuestro desarrollo, hemos constatado que la religión, en el interior de un mundo democrático, constituye un problema: como consignamos en el primer apartado introductorio, en una época signada por la ausencia de un fundamento último que sustente un orden jurídico-político válido, la religión asoma como un sistema de valores y creencias cerrado e incuestionable, que tambalea frente a una era habitada por la incertidumbre. Este carácter problemático de la religión no ha pasado inadvertido para el propio Habermas. Desde sus primeras elaboraciones de la dimensión religiosa hasta sus textos más recientes, aparece como una cuestión a la cual el discurso filosófico debe tomar 
en consideración, pero reconduciéndola a sus propios principios. Por ello, a diferencia de aquella serie de autores que sostiene que existe una ruptura entre las consideraciones tempranas de Habermas en torno a la religión y las elaboraciones más recientes, nosotros hemos sostenido que existe una continuidad entre ambas. Para ello, restituimos las reflexiones del filósofo alemán desde Teoría de la Acción Comunicativa hasta sus ensayos más recientes.

En la segunda sección, hemos observado cómo Habermas tematiza la cuestión de la religión en Teoría de la Acción Comunicativa a partir de la noción de lingüistización de lo sagrado. En un contexto de pérdida del carácter sagrado y normativo de las cosmovisiones religiosas, la lingüistización de lo sagrado alude a un proceso de racionalización comunicativa de los contenidos normativos de la religión, por el cual la fuerza coactiva de lo sagrado se desvanece. De esta manera, el carácter mítico y sagrado de las cosmovisiones religiosas se difumina, sus contenidos normativos se ritualizan y pasan a formar parte del acervo de normas sociales que coaccionan a los individuos de un modo no coercitivo. Con ello, también, la religión y sus contenidos normativos son abiertos a la apropiación reflexiva y a la crítica y, por tanto, se cuentan entre las cuestiones sometidas a la reflexión propia de la razón comunicativa.

En la tercera sección, hemos reconstruido las reflexiones habermasianas más recientes acerca de la religión. En estos textos, Habermas vuelve sobre las posibilidades que se presentan para los discursos religiosos en una era postmetafísica, caracterizada por la aceptación y tolerancia hacia la pluralidad de formas de vida. Respecto de esto, señala Habermas que los discursos religiosos conviven y persisten junto a otro tipo de discursos seculares como los de la filosofía, la sociología, el derecho, etcétera. En este marco, el discurso religioso y el discurso filosófico deben estar abiertos al aprendizaje mutuo. En efecto, el discurso religioso posee contenidos de índole ético y cognitivo que la filosofía puede incorporar, pero que no pueden ser introducidos en el discurso secular en los términos dogmáticos y universalistas en que son planteados por la religión, sino que, antes bien, deben ser tamizados y formulados en un lenguaje accesible para todos, es decir, según Habermas, en el lenguaje de la filosofía.

En la cuarta sección, procuramos mostrar cómo Habermas concibe el rol de la religión hacia el interior del espacio público, específicamente dentro del marco de constituciones liberales seculares, como el de la sociedad norteamericana. Su argumento es que una sociedad verdaderamente liberal debe ser verdaderamente plural. Por ello, debe tomar en consideración los contenidos del discurso religioso, con vistas a promover normas jurídicas vinculantes para todos los ciudadanos, esto es, que no solo incluyan a los ciudadanos no creyentes, sino también a los que pertenecen a una comunidad de creencia. No obstante esto, Habermas retoma su argumento de que dicha incorporación de los contenidos religiosos debe tener lugar a partir de una traducción de dichos contenidos al lenguaje de la filosofía. Esto implicaría abandonar el carácter indiscutido e infalible del discurso religioso para incorporarlo dentro de un esquema lingüístico común a todos y pasible de ser revisado, revocado y modificado. Ahora bien, este argumento conduce a la pregun- 
ta acerca de en qué medida se puede decir que se está tomando en consideración los discursos de la ciudadanía creyente si dicha introducción se produce al precio de la subsunción a otro discurso.

Por ello, nuestra última sección procedió a reconstruir el debate en torno al postsecularismo de Habermas y a proponer una lectura alternativa, que discute con la idea de un "giro postsecular" en la obra del filósofo de la Escuela de Frankfurt. En este último apartado, reconstruimos las hipótesis de una serie de autores que sostienen que Habermas realiza, en sus últimos años, un giro postsecular. En este sentido, a una primera etapa marcadamente secularista, en la cual predomina el intento de reducir toda expresión de la dimensión religiosa, le sucede una posición que reconoce la relevancia de la introducción de contenidos del discurso religioso en el espacio público. A pesar de esto, a nuestro juicio, no existe tal discontinuidad en los planteamientos de Habermas, puesto que la incorporación de los discursos religiosos en el espacio público se produce en desmedro de los contenidos específicos de estos espacios. Es decir, el intento habermasiano de traducir los contenidos del discurso religioso al lenguaje secular de la filosofía no se distingue de la idea de la lingüistización de lo sagrado propia de sus escritos más tempranos. En este sentido, la noción de lo postsecular emerge como un giro meramente nominal que encubre, en el fondo, una axiología pluralista subyacente. Se trata de una axiología, en definitiva, según la cual no existe régimen de discurso que sea más accesible, más plural y más apto que el de la filosofía; una axiología que, en última instancia, acaba por justificar un tipo de discurso y de racionalidad que se aviene a sus propios valores y principios.

\section{Referencias}

1. Las cursivas pertenecen al original, excepto en los casos en los que se indique lo contrario.

2. Por ello, de este tratamiento en torno a la religión se excluyen los fundamentalismos religiosos. Se está pensando, más bien, en aquellas religiones que respetan un pensamiento postmetafísico que no puede afirmar verdades sustanciales en virtud de su reconocimiento de la falibilidad de la razón comunicativa.

3. Para un análisis del problema del multiculturalismo, ver Charles Taylor (2009: 53-116). Allí, Taylor realiza una crítica de ciertas visiones excesivamente procedimentalistas del liberalismo contemporáneo, aunque sin hacer énfasis en la cuestión religiosa. Una respuesta crítica a este texto puede encontrarse en Habermas (1999: 189-227).

4. Ver Camil C. Ungureanu (2013). Para una revisión del problema, orientada fundamentalmente desde la perspectiva de John Rawls, ver Daniel Gamper (2009). Para una recuperación de la cuestión del giro postsecular de Habermas, pero que reconoce el problema señalado, ver Isabel Roldán Gómez (2017). 5. Para una discusión más general del postsecularismo y de lo postsecular, ver Calhoun, Juergensmeyer y Van Antwerpen (2011); Gorski, Kyuman Kim, Torpey y Van Antwerpen (2012).

\section{Bibliografía}

Arendt, H. (1995). Arendt sobre Arendt. Un debate sobre su pensamiento. En H. Arendt, De la historia a la acción (pp. 139-171). Barcelona, España: Paidós.

Berger, P. L. (1999). The Desecularization of the World: Resurgent Religion and World Politics. Michigan, Estados Unidos: Eerdmands Publishing Company.

Casanova, J. (1994). Public Religions in the Modern World. Chicago, Estados Unidos: Chicago University Press. 
Casanova, J. (2000). Religiones públicas en el mundo modernas. Madrid, España: PPC.

Casanova, J. (2008). Reconsiderar la secularización: una perspectiva comparada mundial. Relaciones internacionales: Revista académica cuatrimestral de publicación electrónica, 7, 4-20.

Calhoun, C., Juergensmeyer, M. y Van Antwerpen, J. (Eds.) (2011). Rethinking Secularism. Oxford, Estados Unidos: Oxford University Press.

Estrada, J. A. (2004). Por una ética sin teología. Madrid, España: Trotta.

Gamper, D. (2009) Razón pública y religión en el contexto postsecular. Enrahonar, 43, 111-130.

Gorski, P., Kyuman Kim D., Torpey, J. y Van Antwerpen, J. (2012). The Post-Secular in Question: Religion in Contemporary Society. New York, Estados Unidos: New York University Press.

Habermas, J. (1990). Pensamiento postmetafísico. Madrid, España: Taurus.

Habermas, J. (1992). Teoría de la acción comunicativa II, Madrid, España: Taurus.

Habermas, J. (1999). La lucha por el reconocimiento en el Estado democrático de derecho. En J. Habermas, La inclusión del otro. Estudios de teoría política (pp. 189-227). Barcelona, España: Paidos.

Habermas, J. (2011). Israel o Atenas. Ensayo sobre religión, teología y racionalidad. Madrid, España: Trotta.

Habermas, J. (2006). Entre naturalismo y religión. Barcelona, España: Paidós.

Habermas, J. (2015). Mundo de la vida, política y religión. Madrid, España: Trotta.

Habermas, J. y Ratzinger, J. (2013). Entre razón y religión. Dialéctica de la secularización. México D.F., México: Fondo de Cultura Económica.

Lefort, C. (1988). ¿Permanece lo teológico-político? Buenos Aires, Argentina: Hachette.

Mendieta, E. (2011). La lingüistificación de lo sagrado como catalizador de la modernidad. En J. Habermas, Israel o Atenas. Ensayo sobre religión, teología y racionalidad (pp. 11-56). Madrid, España: Trotta.

Roldán Gómez, I. (2017). Lo postsecular: un concepto normativo. Política y sociedad, 54, 851-867.

Schmitt, C. (2009). Teología política. Madrid, España: Trotta.

Strauss, L. (2008). Jerusalén y Atenas: algunas reflexiones preliminares. En L. Strauss, Estudios de filosofia política platónica (pp. 209-244). Buenos Aires, Argentina: Amorrotu.

Taylor, C. (2009). La política del reconocimiento. En C. Taylor, El multiculturalismo y la política del reconocimiento (pp. 53-116). México D. F., México: Fondo de Cultura Económica.

Ungureanu, C. C. (2013). Razón pública, religión y traducción: prospectivas y límites del postsecularismo de Habermas. Revista Española de Ciencia Política, 32, 183-201.

Weber, M. (1998). Ensayos sobre sociología de la religión I, II y III. Madrid, España: Taurus.

Recibido: 12/06/2019. Aceptado: 20/09/2019.

Franco Castorina, "Entre fe y saber: Habermas y el problema de la religión en una época postsecular". Revista Temas y Debates. ISSN 1666-0714, año 24, número 39, enero-junio 2020, pp. 61-79. 